\title{
Metallic nanoparticles (Cu, Ag, Au) in chalcogenide and oxide glassy matrices: comparative assessment in terms of chemical bonding
}

\author{
O.I. Shpotyuk ${ }^{1-3^{*}}$, M.M. Vakiv ${ }^{1}$, M.V. Shpotyuk ${ }^{5}$, S.A. Kozyukhin ${ }^{4}$ \\ ${ }^{1}$ Institute of Materials of SRC “Carat”, 202 Stryjska str., 79031 Lviv, Ukraine \\ ${ }^{2}$ O.G. Vlokh Institute of Physical Optics, 23, Dragomanov str., 79005 Lviv, Ukraine \\ ${ }^{3}$ Jan Dlugosz University, 13/15 al. Armii Krajowej, Czestochowa, 42200, Poland \\ ${ }^{4}$ N.S. Kurnakov Institute of General and Inorganic Chemistry, \\ 31, Leninsky Pr., Moscow, 199991, Russia \\ ${ }^{5}$ Lviv Polytechnic National University, 12, Bandera str., 79013 Lviv, Ukraine \\ *The corresponding author e-mail: olehshpotyuk@yahoo.com
}

\begin{abstract}
Principal difference in origin of high-order optical non-linearities caused by metallic nanoparticles such as $\mathrm{Cu}, \mathrm{Ag}$ and $\mathrm{Au}$ embedded destructively in oxide- and chalcogenide-type glassy matrices has been analyzed from the viewpoint of semiempirical chemical bond approach. The numerical criterion has been introduced to describe this difference in terms of mean molar bond energies character for chemical interaction between unfettered components of destructed host glassy matrix and embedded guest atoms. It has been shown that "soft" covalent-bonded networks of chalcogenide glasses of As/Ge-S/Se systems differ essentially from glass-forming oxides like silica by impossibility to accommodate agglomerates of metallic nanoparticles. In contrast, such nanostructurized entities can be well stabilized in $\mathrm{Cu}-$, Ag- or Auembedded oxide glasses in full accordance with numerous experimental evidences. Recent unsubstantiated speculations trying to ascribe this ability to fully-saturated covalent matrices of chalcogenide glasses like $\mathrm{As}_{2} \mathrm{~S}_{3}$ are analyzed and criticized as the misleading and inconclusive ones.
\end{abstract}

Keywords: chalcogenide glasses, glass-forming oxides, surface plasmon resonance, nanoparticle, chemical bond.

Manuscript received 23.11.16; revised version received 20.01.17; accepted for publication 01.03.17; published online 05.04.17.

\section{Introduction}

In recent years, the glassy-like composites containing embedded metallic nanoparticles (MNPs) occupy an important niche in modern photonics as promising plasmonic media possessing excellent nonlinear optical properties (increased high-order non-linearities) [1-7]. Electro-magnetic excitations of conduction electrons in nanostructurized metallic entities, exemplified by agglomerates of externally-embedded silver Ag, gold Au or copper $\mathrm{Cu}$ MNPs, result in localized surface plasmon resonance (LSPR), the phenomenon serving as a basis for biomedical sensing with controllable effects on NP size, shape and chemical environment [8]. In this view, chalcogenide glasses (ChG), e.g. melt-quenched vitreous compounds of chalcogens ( $\mathrm{S}, \mathrm{Se}, \mathrm{Te}$, but not $\mathrm{O}$ ) with some elements from IV-V groups of the Periodic Table (Ge, As, Sb, Bi, etc.) [9], which possess few orders higher optical non-linearities as compared with glassforming oxides (GFO) such as fused silica $\mathrm{SiO}_{2}[1,2$, 
10], attract high attention. Therefore, from a device standpoint, the chemical-technological approaches allowing further enhancing these non-linearities in different glassy-like matrices seem very important.

Nowadays, different types of technologies have been employed to enhance optical non-linearities in MNPs-embedded glasses, which include thermalelectrical and optical poling, controllable nucleation and crystallization at nano- and microscales, quenching, laser- and/or electron-driven precipitation of metal ions combined with further heat treatment, as well as ionbeam irradiation (ion implantation) [7, 11-15]. Noteworthy, in view of principally different chemistry, not all of these methods are equally suitable for GFO and $\mathrm{ChG}$.

In general, the methods allowing formation of MNPs in a bulk glass can be grouped in physical, when these additives are directly introduced in a glassy matrix or previously created MNPs are covered with glassy layer [16-18]), and chemical, when MNPs are formed due to in-situ chemical interaction of some precursors with a glassy matrix [19]. Physical methods related with direct embedding MNPs, such as ion beam implantation, are known to be highly destructive to ensure metastable agglomeration of guest MNPs in the host glassy matrix, the degree of destruction being strongly dependent on atomic compactness of the latter [7, 20]. In relatively dense GFO containing great amount of silica $\mathrm{SiO}_{2}[6,7$, $15,20]$ or network ChG composed by close packing of structural polyhedrons interlinked via chalcogen chains (such as $\mathrm{As}_{2} \mathrm{~S}_{3}, \mathrm{As}_{2} \mathrm{Se}_{3}, \mathrm{As} / \mathrm{Ge}-\mathrm{S} / \mathrm{Se}, \mathrm{Ge}-\mathrm{As} / \mathrm{Sb}-\mathrm{S} / \mathrm{Se}$ ) $[10,21]$, the host glassy matrix should be significantly destroyed to accommodate the embedded MNPs. Therefore, the agglomeration occurs under tight chemical interaction between these metallic atoms and components of the destructed glass, the preferential character of this interaction defining geometrical appearance of MNPs (sizes and shapes) and, finally, effect of optical non-linearities.

Thus, the principal difference between GFO and ChG should be carefully examined to clarify expected consequences resulting from embedded MNPs. In this paper, we try to do this from the viewpoint of chemical bond approach [22-24], one of the most productive semiempirical quantitative route providing valuable insight on atomistic arrangement in solids, put forward by Phillips in the earliest 1970s [25].

\section{Chemical bonding disproportionality in a glass}

Distribution of chemical bonds in a host glassy matrix is known to be essentially disturbed under destructive nanostructurization such as ion implantation owing to nuclear collisions of implanted ions with target atoms, destruction of bonds and further deionization transforming metallic $(\mathrm{M})$ ions in neutral atoms [20, 26]. Chemical interaction of embedded $\mathrm{M}$ atoms $(\mathrm{M}=\mathrm{Cu}$, $\mathrm{Ag}, \mathrm{Au}$ ) with unfettered atoms in the glassy-like matrix becomes possible under these conditions resulting in new bond distribution.

For As-based ChG like stoichiometric glassy g$\mathrm{As}_{2}(\mathrm{~S} / \mathrm{Se})_{3}$, the bond balance is governed by thermochemical stability/disproportionality between hetero-to-homonuclear bonding [9]:

$2(\mathrm{As}-\mathrm{S} / \mathrm{Se}) \leftrightarrow(\mathrm{As}-\mathrm{As})+(\mathrm{S} / \mathrm{Se}-\mathrm{S} / \mathrm{Se})$.

The energetic balance of this reaction (1) is leftshifted attaining $40 \mathrm{~kJ} / \mathrm{mol}$ for $\mathrm{g}-\mathrm{As}_{2} \mathrm{~S}_{3}$, as it follows from comparison of mean molar bond energies calculated from standard atomization enthalpies of relevant chemical compounds gathered in Table 1 (such estimation is appreciated within an error-bar of $\pm 10 \mathrm{~kJ} / \mathrm{mol}$ ). Under non-equilibrium conditions (like rapid quenching from high temperatures exceeding the boiling point of $\mathrm{As}_{2} \mathrm{~S}_{3}[9,27-30]$ ), this reaction can stretch towards right side, thus meaning a great amount of "wrong" homonuclear bonds in the As-S alloy (not typical for stoichiometry of As-S system) and other structural defects, such as charged miscoordinated atoms [9]. With transition to $\mathrm{g}-\mathrm{As}_{2} \mathrm{Se}_{3}$, the energetic balance of hetero-to-homo-nuclear bonding (1) is only slightly reduced reaching $35 \mathrm{~kJ} / \mathrm{mol}$.

The similar consideration can be validated for Gebased $\mathrm{ChG}$ like glassy $\mathrm{g}-\mathrm{GeS} / \mathrm{Se}_{2}$, where hetero-tohomonuclear bonding disproportionality can be presented as:

$2(\mathrm{Ge}-\mathrm{S} / \mathrm{Se}) \leftrightarrow(\mathrm{Ge}-\mathrm{Ge})+(\mathrm{S} / \mathrm{Se}-\mathrm{S} / \mathrm{Se})$

The energetic balance of this reaction (2) is also left-shifted with somewhat higher barrier of $65 \mathrm{~kJ} / \mathrm{mol}$ for $\mathrm{g}-\mathrm{GeS}_{2}$ and nearly the same $40 \mathrm{~kJ} / \mathrm{mol}$ for $\mathrm{g}-\mathrm{GeSe}_{2}$.

The character of chemical bonding disproportionality is not principally changed in GFO, where heteronuclear bonds also prevail over the homonuclear ones. However, energetic balance of corresponding hetero-to-homonuclear bonding is strongly enhanced as compared to $\mathrm{ChG}$. Thus, the mean molar energy of Si-O chemical bond in silica (i.e. g$\mathrm{SiO}_{2}$ ) is more than twice favorable than in ChG environment being as high as $465 \mathrm{~kJ} / \mathrm{mol}$ (see Table 1) [9]. Therefore, the chemical bonding disproportionality in this GFO defined as

$2(\mathrm{Si}-\mathrm{O}) \leftrightarrow(\mathrm{Si}-\mathrm{Si})+(\mathrm{O}-\mathrm{O})$.

shifts left towards heteronuclear $\mathrm{Si}-\mathrm{O}$ bonds, subsequently reaching $375 \mathrm{~kJ} / \mathrm{mol}$ in a balance, that is nearly one order higher as in typical $\mathrm{ChG}$.

This remarkable difference allows wider band-gaps in GFO, making them optically transparent and colorless in the visible spectral range. So, it seems reasonable that this energetically favorable structural arrangement can be notably disturbed only by high-energy destructive influences. That is why dielectric GFO like silica $\mathrm{g}-\mathrm{SiO}_{2}$ are often distinguished as "hard" glasses, in an obvious contrast to semiconductor $\mathrm{ChG}$, which are typically termed as "soft" glasses [31]. 


\section{Generalized energetic $\chi$-criterion for chemical bonding in destructed glassy matrices}

The behavior of small amounts of metallic additives in different ChG environment have been remarkably reviewed in the known monograph by Borisova et al. [32] near a three decades ago. In full harmony with this consideration, our preliminary analysis $[33,34]$ shows that difference in the dissociation energies of chemical bonds composing a host glassy matrix for embedded guest $\mathrm{M}$ ions can be parameterized to serve as a signature for preferential chemical bonding in destructed host-quest matrix. Let's generalize this approach to compare the above chemical bonding consideration in respect to reactions (1)-(3) attributed to typical GFO and ChG affected by $\mathrm{M}$ ions implantation.

By signing cation-type and anion-type atoms in a glassy target as $\mathrm{K}$ and $\mathrm{X}$, respectively (so that $\mathrm{K}=\mathrm{Si}$, $\mathrm{As}, \mathrm{Ge}$ and $\mathrm{X}=\mathrm{O}, \mathrm{S}, \mathrm{Se}, \mathrm{Te}$ ), the chemical disproportionality in such a system under implanted metallic atoms $\mathrm{M}(\mathrm{M}=\mathrm{Cu}, \mathrm{Ag}, \mathrm{Au})$ can be presented by analogy with above reactions (1)-(3) via similar heteroto-homonuclear bonding disproportionality

$2(\mathrm{M}-\mathrm{X}) \leftrightarrow(\mathrm{M}-\mathrm{M})+(\mathrm{X}-\mathrm{X})$.

The generalized disproportionality under condition of all chemical interactions possible between existing entities (destructed bonds of host glassy matrix and implanted guest $\mathrm{M}$ ions) can be defined as sequent bond transformation resulting with respect to reactions (1)-(4) in

$2(\mathrm{~K}-\mathrm{X})+(\mathrm{M}-\mathrm{M}) \leftrightarrow(\mathrm{K}-\mathrm{K})+(\mathrm{X}-\mathrm{X})+(\mathrm{M}-\mathrm{M}) \leftrightarrow$ $\leftrightarrow(\mathrm{K}-\mathrm{K})+2(\mathrm{M}-\mathrm{X})$.

Thereby, new balance of chemical bonding in a host glassy matrix possessing preferential heteronuclear $(\mathrm{K}-\mathrm{X})$ environment with embedded destructively $\mathrm{M}$ atoms is stabilized in an equilibrium between left and right sides of the above reaction (5). If energetic barrier $\Delta E$ of his reaction occurs to be positive (right-hand shifted equilibrium), the implanted $M$ atoms destroy existing bond distribution in the host matrix by forming heteronuclear (M-X) bonds at the cost of "wrong" homonuclear $(\mathrm{K}-\mathrm{K})$ ones. Otherwise, the agglomeration of MNPs occurs owing to prevalence of $(\mathrm{M}-\mathrm{M})$ interaction and renovation of destructed $(\mathrm{K}-\mathrm{X})$ bonds.

Thus, we can enter the generalized energetic $\chi$ criterion describing agglomeration of MNPs embedded destructively into the host glassy matrix as

$\chi=2[\mathrm{M}-\mathrm{X}]+[\mathrm{K}-\mathrm{K}]-2[\mathrm{~K}-\mathrm{X}]-[\mathrm{M}-\mathrm{M}]=$

$=2([\mathrm{M}-\mathrm{X}]-[\mathrm{K}-\mathrm{X}])+([\mathrm{K}-\mathrm{K}]-[\mathrm{M}-\mathrm{M}])$,

where notes in square brackets define the mean molar energy of corresponding covalent chemical bonds. The negative values of $\chi$-criterion correspond to agglomeration of MNPs in host glass, while the positive ones are signatures of preferential interaction between $\mathrm{M}$ atoms and unfettered atoms of destructed glass ( $\mathrm{K}$ and $\mathrm{X})$ resulting in a mixed metal-glass matrix.
The mean molar energies of heteronuclear $(\mathrm{M}-\mathrm{X})$ bonds for $\mathrm{M}$ atoms $(\mathrm{M}=\mathrm{Cu}, \mathrm{Ag}, \mathrm{Au})$ in $\mathrm{GFO}$ and $\mathrm{ChG}$ environment calculated as bond dissociation energies in diatomic molecules [35] are given in the comparative diagram in Fig. 1. Under a comparison with Table 1, it is evident these bond energies are essentially reduced as those character for $\mathrm{Si}-\mathrm{O}$ bonds in $\mathrm{g}-\mathrm{SiO}_{2}$, while they are comparable and even slightly greater than dissociation energies of heteronuclear bonds in ChG. It means that under ion implantation the destructed $\mathrm{Si}-\mathrm{O}$ bonds in $\mathrm{g}$ $\mathrm{SiO}_{2}$ will be renewed, facilitating agglomeration of "pure" MNPs in a host bulk (provided implantation dose is sufficient to ensure rather high MNPs excess above the solubility limit $[7,20,26])$. It is worth to note that, in respect to the calculated $\chi$-criterion, agglomeration of $\mathrm{Au}$ MNPs in oxide environment has an obvious preference $(\chi=-480 \mathrm{~kJ} / \mathrm{mol})$ over other metallic additives.

Hence, the $\chi$-criterion for chemical bonding (6) is strongly negative for GFO like silica glass $\mathrm{g}_{-} \mathrm{SiO}_{2}$ (Fig. 1). However, this is not a case of $\mathrm{ChG}$, where $\chi$ criterion is nearly one-order smaller as in GFO. This is clearly revealed for $\mathrm{Cu}$ atoms embedded destructively in environment of As-S, As-Se, Ge-S or Ge-Se chemical bonds. For $\mathrm{Ag}$ and $\mathrm{Au}$ atoms in sulphide $\mathrm{As}-\mathrm{S}$ or $\mathrm{Ge}-\mathrm{S}$ bond environment, the $\chi$-criterion becomes negative, but still does not exceeding a few tens of $\mathrm{kJ} / \mathrm{mol}$. Thus, it means that in all these cases the clustering of MNPs is principally impossible.

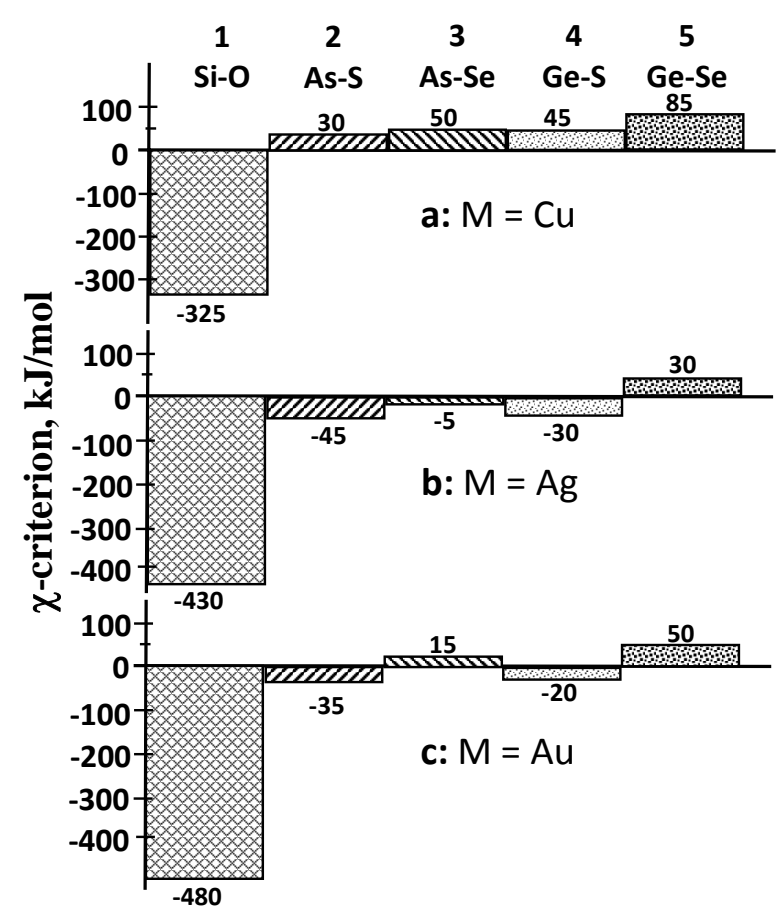

Fig. 1. Comparative diagram of $\chi$-criterion $(\mathrm{kJ} / \mathrm{mol})$ values for $\mathrm{Cu}(\mathrm{a}), \mathrm{Ag}(\mathrm{b})$ and $\mathrm{Au}(\mathrm{c})$ atoms embedded in $\mathrm{Si}-\mathrm{O}(1), \mathrm{As}-$ $\mathrm{S}(2)$, As-Se (3), Ge-S (4) and Ge-Se (5) chemical bond environment. 
Semiconductor Physics, Quantum Electronics \& Optoelectronics, 2017. V. 20, N 1. P. 26-33.

doi: https://doi.org/10.15407/spqeo20.01.026

Table 1. Mean molar bond energies $E$ for main glass-forming cations in oxide and chalcogenide environment [9].

\begin{tabular}{|c|c|c|c|c|c|c|c|}
\hline Bond & $E, \mathrm{~kJ} / \mathrm{mol}$ & Bond & $E, \mathrm{~kJ} / \mathrm{mol}$ & Bond & $E, \mathrm{~kJ} / \mathrm{mol}$ & Bond & $\mathrm{E}, \mathrm{kJ} / \mathrm{mol}$ \\
\hline $\mathrm{As}-\mathrm{As}$ & 200 & $\mathrm{Ge}-\mathrm{Ge}$ & 185 & $\mathrm{Si}-\mathrm{Si}$ & 225 & $\mathrm{O}-\mathrm{O}$ & $330^{*}$ \\
\hline $\mathrm{As}-\mathrm{O}$ & 335 & $\mathrm{Ge}-\mathrm{O}$ & 355 & $\mathrm{Si}-\mathrm{O}$ & 465 & $\mathrm{~S}-\mathrm{S}$ & 280 \\
\hline $\mathrm{As}-\mathrm{S}$ & 260 & $\mathrm{Ge}-\mathrm{S}$ & 265 & $\mathrm{Si}-\mathrm{S}$ & $310^{*}$ & $\mathrm{Se}-\mathrm{Se}$ & 225 \\
\hline $\mathrm{As}-\mathrm{Se}$ & 230 & $\mathrm{Ge}-\mathrm{Se}$ & 225 & $\mathrm{Si}-\mathrm{Se}$ & $270^{*}$ & $\mathrm{Te}-\mathrm{Te}$ & 195 \\
\hline $\mathrm{As}-\mathrm{Te}$ & 205 & $\mathrm{Ge}-\mathrm{Te}$ & 200 & $\mathrm{Si}-\mathrm{Te}$ & 230 & & \\
\hline
\end{tabular}

Note: * - corrected under bond dissociation energies for diatomic molecules taken from [35].

\section{Non-stoichiometry effects in M-embedded ChG matrices}

Noteworthy, the ChG (contrary to GFO) can be subjected to stretched variation in their chemistry allowing non-stoichiometric chalcogen and cation-rich glass-forming alloys [9]. But this specificity does not change essentially the above energetic consideration [36]. Indeed, with account of non-stoichiometry, the generalized disproportionality reaction (5) can be considered separately for intermetallic $(\mathrm{M}-\mathrm{M})$ bonding in heteronuclear $(\mathrm{K}-\mathrm{X})$ and homonuclear $(\mathrm{K}-\mathrm{K})$ and $(\mathrm{X}-$ $\mathrm{X})$ environments, the corresponding reactions being as follows:

$2(\mathrm{~K}-\mathrm{X})+(\mathrm{M}-\mathrm{M}) \leftrightarrow 2(\mathrm{M}-\mathrm{X})+(\mathrm{K}-\mathrm{K})$

$2(\mathrm{X}-\mathrm{X})+(\mathrm{M}-\mathrm{M}) \leftrightarrow 2(\mathrm{M}-\mathrm{X})+(\mathrm{X}-\mathrm{X})$,

$2(\mathrm{~K}-\mathrm{K})+(\mathrm{M}-\mathrm{M}) \leftrightarrow 2(\mathrm{M}-\mathrm{K})+(\mathrm{K}-\mathrm{K})$.

The energetic preference of resulting bond balance in a glass can be estimated by accepting weighting coefficients $\eta$ of different bonds possible under a given structural model:

$\eta_{K-X^{*}}[2(\mathrm{~K}-\mathrm{X})+(\mathrm{M}-\mathrm{M})]+\eta_{X-X^{*}}[2(\mathrm{X}-\mathrm{X})+(\mathrm{M}-\mathrm{M})]+\eta_{K-}$ $K^{\cdot}[2(\mathrm{~K}-\mathrm{K})+(\mathrm{M}-\mathrm{M})] \leftrightarrow$

$\leftrightarrow \eta_{K-X^{*}}[2(\mathrm{M}-\mathrm{X})+(\mathrm{K}-\mathrm{K})]+\eta_{X-X^{*}}[2(\mathrm{M}-\mathrm{X})+(\mathrm{X}-\mathrm{X})]+$

$\eta_{K-K^{*}}[2(\mathrm{M}-\mathrm{K})+(\mathrm{K}-\mathrm{K})]$.

where left side reflects energetic balance of agglomerated MNP within renewed host matrix, and right side corresponds to $\mathrm{M}$ atoms interacting with unfettered atoms of destructed glass.

In real non-stoichiometric $\mathrm{ChG}$ media, chemical interaction between embedded $\mathrm{M}$ and cation-type $\mathrm{K}$ atoms can be ignored in view of smaller bond energies [9], thus resulting in importance of only two first components in both left and right sides of the above reaction (10) to calculate the energetic $\chi$-criterion in non-stoichiometric $\mathrm{ChG}$ matrices:

$\chi^{\mathrm{nst}}=\eta_{K-X^{\prime}}[2(\mathrm{M}-\mathrm{X})+(\mathrm{K}-\mathrm{K})]+\eta_{X-X^{*}}[2(\mathrm{M}-\mathrm{X})+(\mathrm{X}-\mathrm{X})]-$

$-\eta_{K-X}[2(\mathrm{~K}-\mathrm{X})+(\mathrm{M}-\mathrm{M})]-\eta_{X-X}[2(\mathrm{X}-\mathrm{X})+(\mathrm{M}-\mathrm{M})]=$

$=\eta_{K-X}[2(\mathrm{M}-\mathrm{X})-2(\mathrm{~K}-\mathrm{X})+(\mathrm{K}-\mathrm{K})-(\mathrm{M}-\mathrm{M})]+\eta_{X-}$

$x^{*}[2(\mathrm{M}-\mathrm{X})-(\mathrm{X}-\mathrm{X})-(\mathrm{M}-\mathrm{M})]$.
Table 2. Mean molar bond energies $E(\mathrm{~kJ} / \mathrm{mol})$ of metallic atoms $(\mathrm{M}=\mathrm{Cu}, \mathrm{Ag}, \mathrm{Au})$ in $\mathrm{GFO}$ and $\mathrm{ChG}$ environment [35].

\begin{tabular}{|c|c|c|c|c|c|}
\hline Bond & $\begin{array}{c}E, \\
\mathrm{~kJ} / \mathrm{mol}\end{array}$ & Bond & $\begin{array}{c}E, \\
\mathrm{~kJ} / \mathrm{mol}\end{array}$ & Bond & $\begin{array}{c}\mathrm{E}, \\
\mathrm{kJ} / \mathrm{mol}\end{array}$ \\
\hline $\mathrm{Cu}-\mathrm{Cu}$ & 200 & $\mathrm{Ag}-\mathrm{Ag}$ & 165 & $\mathrm{Au}-\mathrm{Au}$ & 225 \\
\hline $\mathrm{Cu}-\mathrm{O}$ & 290 & $\mathrm{Ag}-\mathrm{O}$ & 220 & $\mathrm{Au}-\mathrm{O}$ & 225 \\
\hline $\mathrm{Cu}-\mathrm{S}$ & 275 & $\mathrm{Ag}-\mathrm{S}$ & 220 & $\mathrm{Au}-\mathrm{S}$ & 255 \\
\hline $\mathrm{Cu}-\mathrm{Se}$ & 255 & $\mathrm{Ag}-\mathrm{Se}$ & 210 & $\mathrm{Au}-\mathrm{Se}$ & 250 \\
\hline
\end{tabular}

Accepting the values of molar bond energies summarized in Tables 1 and 2 for $\mathrm{ChG}$ within the chemically ordered covalent network model (COCNM) [9], it can be easily shown that over-stoichiometric chalcogen atoms only enhances $\chi$-criterion, facilitating incorporation of $\mathrm{M}$ atoms into the glass matrix, while over-stoichiometric As or Ge has no essential effect on chemical bonds.

So, destructed bonds in host ChG matrix do not recover after destruction, being replaced by more energetically favorable $(\mathrm{M}-\mathrm{X})$ bonds. This process results in extraction of metal chalcogenide phase instead of "pure" MNPs. Excess K atoms appearing under this destruction migrate towards surface for further interaction with environment. Undoubtedly, just this impurity interaction is responsible for $\mathrm{As}_{2} \mathrm{O}_{3}$ extraction at the surface of $\mathrm{g}-\mathrm{As}_{2} \mathrm{~S}_{3}$ under prolonged $\gamma$-irradiation in ambient conditions $[36,37]$. Similar changes occur also in Ge-based ChG affected by $c w$ laser illumination [38].

\section{Experimental evidences on MNPs formation in glassy substances}

The above consideration with energetic $\chi$-criterion for MNPs clustering in a glass (6) concerns destructed host glassy matrices, when chemical interaction between some unfettered atoms of glassy target and embedded $\mathrm{M}$ atoms cannot be neglected. As it occurs in GFO (or other alternative media with high negative $\chi$-criterions like those given in diagram in Fig. 1 for $\mathrm{M}=\mathrm{Cu}, \mathrm{Ag}, \mathrm{Au}$ in Si-O bonding environment), ion implantation or other 
destructive technology results in agglomeration of MNPs, this process being defined by destruction efficiency of host matrix (like dose and energy of implanted ions). Typical variants of practical realization of these nanostructurization technologies can be well exemplified by research of Stepanov with co-authors [7, 20,26] showing enhancement of optical non-linearities in oxide dielectric media due to ion-synthesized MNPs.

However, this is not a case of nanostructurization under non-disturbed (or partially disturbed) bond balance in a host glassy matrix, which possibly occurs under positive values of $\chi$-criterion presented in Fig. 1 for $\mathrm{M}$ atoms in ChG-type bonding. The latter can be illustrated by $\mathrm{ChG}$ deposition on MNPs initially formed at a surface of dielectric substrate, when upper glassy film play the role of a covering layer ensuring necessary difference in the refractive index $n$ with MNPs [16-18]. Because of lack of essential disturbances in chemical interaction within MNPs themselves and neighboring medium, Kokenyesi with co-authors [16-18] observe, in fact, the islands of embedded MNPs in homogeneous ChG environment.

Chemical interactions are also partially suppressed under condition of photostimulated diffusion of $\mathrm{M}$ atoms (mainly $\mathrm{Ag}$ and $\mathrm{Cu}$ ) into $\mathrm{ChG}$ films [39-41], the famous research launched by Kostishin with co-authors [39] nearly a half century ago. Light illumination causes local misbalance of negative-positive electrical charge in the film due to excitation of chalcogen lone-pair electrons, resulting in transfer of electrically neutral $\mathrm{M}$ atom into positively-charged $\mathrm{M}^{+}$ions [40]. These $\mathrm{M}^{+}$ions diffuse along sites of chalcogen atoms, thus leaving principal glass-forming structural units without essential changes, as it was convincingly proved by Stronski with coauthors [41] for Ag-photodoped $\mathrm{As}_{2} \mathrm{~S}_{3}$ films. The $\mathrm{M}$ additives stretch in a host amorphous matrix, being involved preferentially in coordinative bonding with chalcogen atoms along their diffusion paths, whereas normal covalent bonding occurs only near structural defects [41]. Doubtless, if point getters for guest $\mathrm{M}^{+}$ions were stabilized in host $\mathrm{ChG}$ film, it could be possible to create photoexposure-guided agglomerates of MNPs.

Other example concerns the case, when chemical host-quest interaction can be ignored due to looser (inhomogeneous) structures of some glassy-like targets. Such research can be well exemplified by experiments on Ag-ions implantation in chalcohalide matrices performed by Liu et al. [42, 43]. It was found that in $56 \mathrm{GeS}_{2}-24 \mathrm{Ga}_{2} \mathrm{~S}_{3}-20 \mathrm{KBr}$ glass $\mathrm{Ag}$ ions embedded under implantation with varied doses from $10^{16}$ to $2 \cdot 10^{17}$ ions $/ \mathrm{cm}^{2}$ can be agglomerated presumably in inner spaces of lower densities, which allow appearance of relatively large MNPs agglomerates reaching in sizes even a few hundred nanometers. The enhanced thirdorder optical non-linearities in these nanostructurized chalcohalide glasses were shown to correlate strongly with ion implantation doses and geometrical sizes of agglomerated Ag MNPs [42, 43]. Recently [44], it was shown that similar results could be achieved under Ag ions implantation in melt-quenched $72 \mathrm{GeS}_{2}-18 \mathrm{Ga}_{2} \mathrm{~S}_{3}$ $10 \mathrm{CdS}$ glass, the typical sizes of Ag MNPs being ranged from $\sim 90 \mathrm{~nm}$ (at $10^{16}$ ions $/ \mathrm{cm}^{2}$ dose) to $300 \mathrm{~nm}$ (at $2 \cdot 10^{17}$ ions $/ \mathrm{cm}^{2}$ dose). This glassy target does not belong to typical structurally-homogeneous $\mathrm{ChG}$ like g$\mathrm{As}_{2}(\mathrm{~S} / \mathrm{Se})_{3}$ possessing glass-forming network with fully saturated and uniform covalent bonding (for more details, see $[9,45]$ and literature therein). Appearance of large agglomerates of Ag MNPs in this case follows from principal difference in chemical interaction between embedded $\mathrm{Ag}$ ions and structurally-specific glass components.

In an obvious contrast to the above argumentation, we should also consider here the example on MNPs clustering in $\mathrm{ChG}$ media in a denial sense as a result of misleading speculations of some authors [46-48] trying to ascribe unique clustering ability to $\mathrm{M}$ atoms embedded destructively in all glassy substances (both GFO and $\mathrm{ChG}$ ) despite their chemical nature. Thus, Kavetskyy with co-authors [46] claimed recently a principal possibility to form agglomerates of ionimplanted $\mathrm{Cu}$ MNPs in $\mathrm{g}-\mathrm{As}_{2} \mathrm{~S}_{3}$ and $\mathrm{g}-\mathrm{Ge}_{15.8} \mathrm{As}_{21} \mathrm{~S}_{63.2}$ like it occurred in silica glass $\mathrm{g}-\mathrm{SiO}_{2}$ [15]. They asserted that $\mathrm{Cu}$ MNPs could be gathered in spherical entities of only 5 to $10 \mathrm{~nm}$ in radius, giving essential changes in optical linear absorption at $\sim 580 \ldots 590 \mathrm{~nm}$ and response in nonlinear optical properties observed in Z-scan measurements. However, even preliminary and very unscrupulous insight gives an uncontroversial prove on speculative character of such "conclusions".

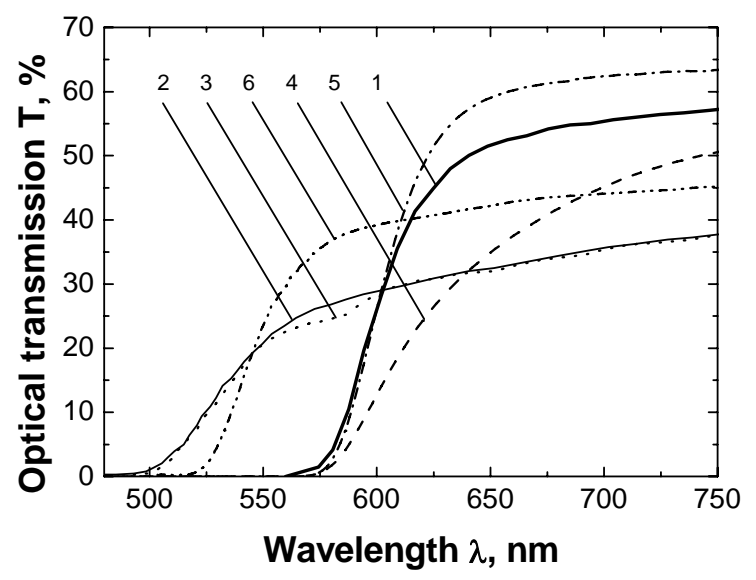

Fig. 2. Comparison of optical transmission spectra of As-S $\mathrm{ChG}$ (all the samples are $\sim 1.0 \mathrm{~mm}$ in thickness): $\mathrm{g}-\mathrm{As}_{2} \mathrm{~S}_{3}$ before $\gamma$-irradiation (1) as compared with that of Fig. 14.1 from Ref. [48], g- $\mathrm{As}_{2} \mathrm{~S}_{3}$ before (2) and after $\mathrm{Cu}^{+}$ion implantation with $1.5 \cdot 10^{17} \mathrm{~cm}^{-2}$ dose (3) as compared with that of Fig. 14.7 from Ref. [48]; $\mathrm{g}-\mathrm{As}_{2} \mathrm{~S}_{3}$ prepared, respectively, by quenching from high-temperature $900{ }^{\circ} \mathrm{C}(4)$ or low-temperature $500{ }^{\circ} \mathrm{C}$ state (5) as compared with that of Ref. [30]; S-rich g- $\mathrm{As}_{22} \mathrm{~S}_{78}$ affected by phase separation caused by long-tern aging (6) as compared with that of Ref. [52]. The spectral positions of optical transmission edges were reproduced without measuring points directly from indicated sources. 
First, the characteristic band of LSPR for $\mathrm{Cu}$ MNPs in $\mathrm{g}-\mathrm{As}_{2} \mathrm{~S}_{3}$ with the refraction index $n \cong 2.5$ was attributed to $\sim 580 \ldots 590 \mathrm{~nm}$ domain, which is the characteristic frequency of LSPR in oxide environment with much smaller $n$ (below 2.0) [7]. In concomitance with oxide matrices (such as $\mathrm{SiO}_{2}, \mathrm{Al}_{2} \mathrm{O}_{3}, \mathrm{ZnO}$, etc.) [7, $15,26]$, this LSPR band positioned in accordance to known formula for spherical MNPs [49] should be expected in $\mathrm{ChG}$ with refraction indices $n>2.4$ only at longer wavelengths (more than $620 \ldots 630 \mathrm{~nm}$ ), but not at the shorter ones $(\sim 580 \ldots 590 \mathrm{~nm})$.

Second, the results of Z-scan patterning (which was presented as a main evidence for enhanced optical nonlinearities in [46-48]) were given only for $\mathrm{Cu}$ implanted $\mathrm{ChG}$ affected by laser irradiation at various intensities, but not compared with parent non-implanted specimen. So, it was impossible at all to conclude (even intuitively) on probable origin of this "effect". As an example of rational and unbiased consideration on this issue, we refer to known works of Almeida et al. $[50,51]$ on open aperture Z-scan signatures of nonlinear optical absorption caused by Au MNPs in heavy-metal oxide glasses of $\mathrm{GB}$ type (i.e. $\mathrm{GeO}_{2}-\mathrm{Bi}_{2} \mathrm{O}_{3}$ ). All these evidences were always grounded on reliable comparison between non-affected (parent) GB glasses and these glasses affected by embedded Au MNPs (GB-Au). Such experimental purity including obligatory comparison with reference specimen (non-affected or parent) was also a necessary condition for conclusion on third-order optical non-linearity from ion-implanted Ag MNPs in the cited Liu's research [42-44].

Third, it seems doubtful (if any) to adopt unambiguously that optical transmission spectrum in [4648] can be really ascribed to stoichiometric $\mathrm{g}-\mathrm{As}_{2} \mathrm{~S}_{3}$ of $\sim 1 \mathrm{~mm}$ in thickness. For more convincing argumentation on this issue, different optical transmission spectra for As$\mathrm{S}$ ChG taken additionally from $[30,52]$ are compared as depicted in Fig. 2. As a top of full misunderstanding, it should be emphasized huge difference of more than $50 \mathrm{~nm}(!)$ in the wavelength position of optical transmission edge for the same $\mathrm{g}-\mathrm{As}_{2} \mathrm{~S}_{3}$ measured before ion implantation and gamma-irradiation in Ref. [48]. Comparison with $\mathrm{ChG}$ prepared in different quenching regimes [30] testifies that latter is rather appropriate for $\mathrm{g}$ $\mathrm{As}_{2} \mathrm{~S}_{3}$, but not spectra depicting short-wave optical transmittance $(500 \ldots 550 \mathrm{~nm})$ in Ref. [46-48]. Within careful inspection of As-S system [52], it seems that only non-stoichiometric S-rich ChG transmit incident light near $\sim 500 \mathrm{~nm}$, but at obviously higher transparency (as compared with that of the Fresnel formula [53], the 69\% in optical transmission corresponds to refractive index $n \cong 2.5$ ). So, their allegation on ion implantation in $\mathrm{g}$ $\mathrm{As}_{2} \mathrm{~S}_{3}$ [46-48] is roughly falsified and simply speculative.

It was also strange why implantation in [46-48] arranged at higher doses $\left(10^{17} \mathrm{ion} / \mathrm{cm}^{2}\right)$ did not change optical transmission of implanted $\mathrm{ChG}$ giving point-topoint coincidence with data for initial non-implanted $\mathrm{ChG}$ in the whole spectral range excepting the $580 \ldots 590 \mathrm{~nm}$ part (see Fig. 2). So, it seems that the authors of [46-48] deal with inhomogeneous $\mathrm{ChG}$ (probably, one of Senriched compositions close to $\mathrm{g}-\mathrm{As}_{2} \mathrm{~S}_{8}$, provided $\mathrm{ChG}$ of As-S system was really used), which have been destructed just preliminary, i.e. before implantation (maybe due to poor mechanical treatment or invalid quenching route applied to stabilize $\mathrm{ChG}$ ), and thus their claim on full identity between ion implantation in GFO and $\mathrm{ChG}$ is entirely misleading and inconclusive.

\section{Conclusions}

In summary, we would like to underline the principal difference in the origin of high-order optical nonlinearities related with metallic nanoparticles embedded destructively in oxide- and chalcogenide glassy matrices. The chemical bonding approach is adequately applied to describe this difference in terms of the mean molar bond energies typical for interaction between unfettered atoms of host glassy network and embedded guest atoms $(\mathrm{Cu}$, $\mathrm{Ag}, \mathrm{Au})$. Corresponding energetic barriers of bond disproportionality for metallic atoms defined as $\chi$ criterion occur to be principally different in oxide and chalcogenide environment. These findings are in full agreement with numerous experiments exploring destructive and non-destructive mechanisms of embedding the metallic nanoparticles, but contradict principally to misleading speculations with unproved schemes for nanostructurization in ion-implanted chalcogenide glass networks.

\section{Acknowledgement}

The authors acknowledge support from Science and Technology Center in Ukraine under Pr. No 6174. Discussions on surface plasmon resonance in noblemetal media with N. Dmitruk and I. Blonskyy, as well as helpful comments on optical nonlinearities in glasses from V. Kadan are kindly acknowledged.

\section{References}

1. Zakery A., Elliott S.R. Optical Non-linearities in Chalcogenide Glasses and their Applications. Berlin-Heidelberg, Springer-Verlag, 2007.

2. Zakery A., Shafmirzaee H. Modeling of enhancement of nonlinearity in oxide and chalcogenide glasses by introduction of nanometals. Phys. Lett. A. 2007. 36. P. 484-487.

3. Tanaka K. Optical nonlinearity in photonic glasses. $J$. Mater. Sci.: Mater. Electron. 2005. 16. P. 633-643.

4. Tao H., Zhao X., Liu Q. Optical non-linearity in nano- and micro-crystallized glasses. J. Non-Cryst. Solids. 2013. 377. P. 146-150.

5. Ogusu K., Shinkawa K. Optical nonlinearities in $\mathrm{As}_{2} \mathrm{Se}_{3}$ chalcogenide glasses with $\mathrm{Cu}$ and $\mathrm{Ag}$ for pulse durations on the order of nanoseconds. Opt. Exp. 2009. 17. P. 8165-8172. 
6. Ganeev R.A., Ryasnyansky A.I. Nonlinear optical characteristics of nanoparticles in suspensions and solid matrices. Appl. Phys. B. 2006. 84. P. 295-302.

7. Stepanov A.L. Nonlinear optical properties of implanted metal nanoparticles in various transparent matrixes: A review. Rev. Adv. Mater. Sci. 2011. 27. P. 115-145.

8. Anker J.N., Hall W.P., Lyandres O., Chan N.C., Zhao J., Van Duyne R.P. Biosensing with plasmonic nanosensors. Nature Materials. 2006. 7. P. 442-453.

9. Feltz A. Amorphous Inorganic Materials and Glasses. VCH Publ., New York, 1993.

10. Liu Q., Zhao X. Non-linear optical properties of chalcogenide and chalcohalide glasses. J. NonCryst. Solids. 2010. 356. P. 2375-2377.

11. Grabiec M., Wolak A., Veron O., Blondeau J.-P., Pellerin N., Allix M., Pellerin S., Dzierzega K. Laser-driven precipitation of silver nanoparticles in soda lime glass matrix monitored by on-line extinction measurements. Plasmonics. 2012. 7. P. 279-286.

12. Podsvirov O.A., Sidorov A.I., Tsekhomskii V.A., Vostokov A.V. Formation of copper nanocrystals in photochromic glasses under electron irradiation and heat treatment. Phys. Solid State. 2010. 52. P. 1906-1909.

13. Rycenga M., Cobley C.M., Zeng J., Li W., Moran C.H., Zhang Q., Qin D., Xia Y. Controlling the synthesis and assembly of silver nanostructures for plasmonic applications. Chem. Rev. 2011. 111. P. 3669-3712.

14. Zeng H., Zhao C., Qiu J., Yang Y., Chen G. Preparation and optical properties of silver nanoparticles induced by a femtosecond laser irradiation. J. Non-Cryst. Solids. 2007. 300. P. 519522.

15. Ganeev R.A., Ryasnyansky A.I., Stepanov A.L., Usmanov T. Saturated absorption and reverse saturated absorption of $\mathrm{Cu}: \mathrm{SiO}_{2}$ at $\lambda=532 \mathrm{~nm}$. phys. status solidi (b). 2004. 241. P. R1-R4.

16. Charnovych S., Kokenyesi S., Glodán Gy., Csik A. Enhancement of photoinduced transformations in amorphous chalcogenide film via surface plasmon resonances. Thin Solid Films. 2011. 519. P. 43094312.

17. Charnovych S., Dmitruk N., Voynarovych I., Yurkovich N., Kokenyesi S. Plasmon-assisted transformations in metal-amorphous chalcogenide light-sensitive nanostructures. Plasmonics. 2012. 7. P. 341-345.

18. Charnovych S., Dmitruk N., Yurkovich N., Shiplyak M., Kokenyesi S. Photo-induced changes in a$\mathrm{As}_{2} \mathrm{~S}_{3} /$ gold nanoparticle composite layer structures. Thin Solid Films. 2013. 548. P. 419-424.

19. Burunkova J., Csarnovics I., Denisyuk I., Daroczi L., Kokenyesi S. Enhancement of laser recording in gold/amorphous chalcogenide and gold/acrylate nanocomposite layers. J. Non-Cryst. Solids. 2014. 402. P. 200-203.
20. Stepanov A.L. Peculiarities of synthesis of metal nanoparticles in dielectrics by ion implantation method. Vestnik Nizhegorod. Univ.: Ser. Fizika Tverd. Tela. 2003. 1. P. 82-88 (in Russian).

21. Nasu H., Kubodera K., Kobayashi M., Nakamura M., Kamiya K. Third-harmonic generation from some chalcogenide glasses. J. Amer. Ceram. Soc. 1990. 73, P. 1794-1796.

22. Bicerano J., Ovshinsky S.R. Chemical bond approach to the structures of chalcogenide glasses with reversible switching properties. J. Non-Cryst. Solids. 1985. 74. P. 75-84.

23. Tichy L., Ticha H. Covalent bond approach to the glass-transition temperature of chalcogenide glasses. J. Non-Cryst. Solids. 1995. 189. P. 141146.

24. Kastner M. Compositional trends in the optical properties of amorphous lone-pair semiconductors. Phys. Rev. B. 1973. 7. P. 5237-5252.

25. Phillips J.C. Ionicity of the chemical bond in crystals. Rev. Mod. Phys. 1970. 42. P. 317-356.

26. Stepanov A.L., Khaibullin I.B. Fabrication of metal nanoparticles in sapphire by low-energy ion implantation. Rev. Adv. Mater. Sci. 2005. 9. P. 109-129.

27. Yang C.Y., Sayers D.E., Paesler M.A. X-rayabsorption spectroscopy studies of glassy $\mathrm{As}_{2} \mathrm{~S}_{3}$. The role of rapid quenching. Phys. Rev. B. 1987. 36. P. 8122-8128.

28. Kuznetsov S.L., Mikhailov M.D., Pecheritsyn I.M., Turkina E.Yu. Structural chemical processes at the synthesis of chalcogenide glasses. J. Non-Cryst. Solids. 1997. 213-214. P. 68-71.

29. Mamedov S., Kisliuk A., Quitmann D. Effect of preparation conditions on the low frequency Raman spectrum of glassy $\mathrm{As}_{2} \mathrm{~S}_{3}$. J. Mater. Sci. 1998. 33. P. 41-43.

30. Shpotyuk O., Kozyukhin S., Shpotyuk Ya., Demchenko P., Mitsa V., Veres M. Coordination disordering in near-stoichiometric arsenic sulfide glass. J. Non-Cryst. Solids. 2014. 402. P. 236-243.

31. Musgraves J.D., Richardson K., Jain H. Laserinduced structural modification, its mechanisms, and applications in glassy optical materials. Opt. Meter. Exp. 2011. 1. P. 921-935.

32. Borisova Z.U., Bychkov E.A., Tverianovich Yu.S. Interaction of Metals with Chalcogenide Glasses. Leningrad State University Publ., 1991 (in Russian).

33. Shpotyuk O., Shpotyuk M., Cebulski J. On the energetic criterion for destructive clustering of metallic nanoparticles in chalcogenide and oxide glassy matrices. phys. status solidi (b). 2016. 253. P. 494-498.

34. Shpotyuk M.V., Shpotyuk O.I., Cebulski J., Kozyukhin S. Destructive clustering of metal nanoparticles in chalcogenide and oxide glassy matrices. Nanoscale Res. Lett. 2016. 11. P. 34-134-6. 
35. Luo Y.-R. Comprehensive Handbook of Chemical Bond Energies. Taylor \& Francis Group, CRC Press: Boca Raton, 2007.

36. Shpotyuk M., Shpotyuk O., Golovchak R., Demchenko P. FSDP-related correlations in $\gamma$ irradiated chalcogenide semiconductor glasses: The case of glassy arsenic trisulphide $\mathrm{g}-\mathrm{As}_{2} \mathrm{~S}_{3}$ revised. J. Phys. Chem. Solids. 2013. 74. P. 1721-1725.

37. Shpotyuk M., Shpotyuk O., Serkiz R., Demchenko P., Kozyukhin S. Surface oxidation in glassy arsenic trisulphide induced by high-energy $\gamma$-irradiation. Rad. Phys. Chem. 2014. 97. P. 341-345.

38. Lovas G., Mitsa V., Holomb R., Rosola I., Borkach E. The room temperature visible photoluminescence in $\mathrm{g}-\mathrm{As}_{2} \mathrm{~S}_{3}$ and Ge-based glasses. Sci. Bull. Uzhgorod Univ. Ser. Fiz. 2013. 34. P. 54-58.

39. Kostishin M.T., Michailovskaya E.V., Romanenko P.F. On the effect of photographic sensitivity of thin semiconductor layers on the metal substrate. Sov. Phys. Solid State. 1966. 8. P. 571-576.

40. Elliott S.R. Photodissolution of metals in chalcogenide glasses: a unified mechanism. J. NonCryst. Solids. 1991. 137-138. P. 1031-1034.

41. Stronski A.V., Vlcek M., Stetsun A.I., Sklenar A., Shepeliavyj P.E. Raman spectra of Ag- and $\mathrm{Cu}-$ photodoped chalcogenide films. Semiconductor Physics, Quantum Electronics and Optoelectronics. 1990. 2. P. 63-68.

42. Liu Q., He X., Zhao X., Ren F., Xiao X., Jiang C., Zhou H., Zhao X., Lu L., Qian S. Third-order nonlinearity in Ag-nanoparticles embedded $56 \mathrm{GeS}_{2}-24 \mathrm{Ga}_{2} \mathrm{~S}_{3}-20 \mathrm{KBr}$ chalcohalide glass. $J$. Non-Cryst. Solids. 2011. 357. P. 2320-2323.

43. Liu Q., He X., Zhao X., Ren F., Xiao X., Jiang C., Zhou X., Lu L., Zhou H., Qian S., Poumellec B., Lancry M. Enhancement of third-order nonlinearity in Ag-nanoparticles-contained chalcohalide glass. J. Nanopart. Res. 2011. 13. P. 3693-3697.

44. Song M., Liu Q.M., Xu Gai G., Ren F. Enhancement of third-order optical nonlinearities in $72 \mathrm{GeS}_{2}$ $18 \mathrm{Ga}_{2} \mathrm{~S}_{3}-10 \mathrm{CdS}$ glasses by ion implantation. Chalcogenide Lett. 2015. 12. P. 453-460.
45. Shpotyuk O., Golovchak R., Kozdras A. Physical ageing of chalcogenide glasses, in: Chalcogenide Glasses: Preparation, Properties and Applications, Eds. J.-L. Adam, X. Zhang. Woodhead Publishing series in electronic and optical materials. Oxford: Woodhead Publishing, 2014. P. 209-264.

46. Kavetskyy T.S., Valeev V.F., Nuzhdin V.I., Tsmots V.M., Stepanov A.L. Optical properties of chalcogenide glasses with ion-synthesized copper nanoparticles. Techn. Phys. Lett. 2013. 39. P. 1-4.

47. Kavetskyy T., Stepanov A.L., Bazarov V.V., Tsmots V., Ren J., Chen G., Zhao X. Comparative study of optical properties of polarizing oxide glasses with silver nanorods and chalcogenide glasses with copper nanoparticles. Phys. Procedia. 2013. 48. P. 191-195.

48. Kavetskyy T.S., Stepanov A.L. Effects of gammairradiation and ion implantation in chalcogenide glasses. Chapter 14, in: Glass Nanocomposites: Synthesis, Properties and Applications. Eds. B. Karmakar, K. Rademann, A.L. Stepanov. Elsevier Acad. Press, 2016. P. 341-358.

49. Blonskyy I.V. Femtooptics of films and nanoparticles of noble metals. Ukr. J. Phys. Repts. 2009. 5. P. 170-202.

50. Almeida J.M.P., da Silva D.S., Kassab L.R.P., Zilio S.C., Mendonça C.R., De Boni L. Ultrafast thirdorder optical nonlinearities of heavy metal oxide glasses containing gold nanoparticles. Opt. Mater. 2014. 36. P. 829-832.

51. Almeida J.M.P., Almeida G.F.B., Boni L., Mendonça C.R. Nonlinear optical properties and femtosecond laser micromachining of special glasses. J. Braz. Chem. Soc. 2015. 26. P. 2418 2429.

52. Golovchak R., Shpotyuk O., McCloy J.S., Riley B.J., Windisch C.F., Sundaram S.K., Kovalskiy A., Jain H. Structural model of homogeneous As-S glasses derived from Raman spectroscopy and highresolution XPS. Phil. Mag. 2010. 90. P. 4489-4501.

53. Born M., Wolf E. Principles of Optics. Cambridge Univ. Press, Cambridge, 1999. 